\title{
Adalimumab Dose-Escalation Therapy Is Effective in Refractory Crohn's Disease Patients with Loss of Response to Adalimumab, Especially in Cases without Previous Infliximab Treatment
}

\author{
Taketo Suzuki $^{\mathrm{a}}$ Tsutomu Mizoshita ${ }^{\mathrm{a}}$ Tomoya Sugiyama $^{\mathrm{b}}$ \\ Yoshikazu Hirata ${ }^{c}$ Yoshihide Kimura ${ }^{d}$ Yuka Suzukie,g \\ Tomonori Yamada $^{e}$ Hironobu Tsukamoto ${ }^{f}$ Takashi Mizushima $^{f}$ \\ Naomi Sugimura ${ }^{a}$ Takahito Katano ${ }^{a}$ Satoshi Tanida ${ }^{a}$ Hiromi Kataoka ${ }^{a}$ \\ Makoto Sasaki ${ }^{\text {b }}$ \\ aDepartment of Gastroenterology and Metabolism, Nagoya City University Graduate \\ School of Medical Sciences, Nagoya, Japan; b Department of Gastroenterology, Aichi \\ Medical University School of Medicine, Nagakute, Japan; 'Department of \\ Gastroenterology, Kasugai Municipal Hospital, Kasugai, Japan; dDepartment of \\ Gastroenterology, Nagoya City West Medical Center, Nagoya, Japan; ${ }^{\text {DDepartment of }}$ \\ Gastroenterology, Japanese Red Cross Nagoya Daini Hospital, Nagoya, Japan; \\ fDepartment of Gastroenterology, Gifu Prefectural Tajimi Hospital, Tajimi, Japan; \\ gDepartment of Gastroenterology, Nagoya Memorial Hospital, Nagoya, Japan
}

\section{Keywords}

Crohn's disease $\cdot$ Adalimumab dose escalation · Loss of response 


\section{Case Reports in Gastroenterology}

Case Rep Gastroenterol 2019;13:37-49

DOI: $10.1159 / 000496453$

( 2019 The Author(s). Published by S. Karger AG, Base www.karger.com/crg

Suzuki et al.: Adalimumab Dose-Escalation Therapy Is Effective in Refractory Crohn's Disease Patients with Loss of Response to Adalimumab, Especially in Cases without

Previous Infliximab Treatment

\begin{abstract}
Background/Aims: Adalimumab dose escalation is one of the most important options in refractory Crohn's disease patients with loss of response to adalimumab. The goal of this study was to evaluate the effectiveness of adalimumab dose escalation in Crohn's disease patients with loss of response to adalimumab, since there are few reports of adalimumab dose escalation, especially in East Asia. Methods: The clinical response to adalimumab dose escalation in Crohn's disease patients with loss of response to adalimumab was evaluated retrospectively, using the Crohn's disease activity index score, serum C-reactive protein levels, and endoscopic analyses. Results: Of the 203 Crohn's disease patients treated with anti-tumor necrosis factor, 14 refractory Crohn's disease patients with loss of response to adalimumab received adalimumab dose-escalation therapy. The $\mathrm{C}$-reactive protein level was significantly reduced from the start to weeks 12 and 52 of adalimumab dose escalation in the whole group, although there were no significant reductions of Crohn's disease activity index scores. Both Crohn's disease activity index scores and C-reactive protein levels were significantly reduced from the start to weeks 12 and 52 of adalimumab dose escalation in patients without previous infliximab treatment, although C-reactive protein levels were positive in all cases with previous infliximab exposure at weeks 12 and 52. Endoscopic mucosal healing was achieved with adalimumab dose escalation in 2 cases without previous infliximab treatment. Conclusions: Adalimumab dose-escalation therapy is effective in refractory Crohn's disease patients with loss of response to adalimumab, especially in cases without previous infliximab treatment.
\end{abstract}

(C) 2019 The Author(s)

Published by S. Karger AG, Basel

\title{
Introduction
}

Crohn's disease (CD) is a chronic inflammatory bowel disease that is characterized by mucosal inflammation of the gastrointestinal tract with periods of relapse and remission. Obtaining long-term deep remission is essential to prevent irreversible gastrointestinal damage and disability [1,2]. Inhibition of tumor necrosis factor (TNF)- $\alpha$ is very important for the control of inflammatory lesions in CD, and subcutaneous adalimumab (ADA) is one of the most important drugs approved for the treatment of CD [3]. ADA is effective for the induction and maintenance of clinical remission in patients with moderate-to-severe $\mathrm{CD}$, particularly in cases naïve to anti-TNF treatment [4-6].

Although anti-TNF therapies are effective for the medical management of CD, a significant percentage of patients who initially respond to the anti-TNF induction regimen lose their response over time, so-called loss of response (LOR). The LOR rate is $13 \%$ per patient-year with infliximab (IFX) [7] and 20.3\% per patient-year with ADA [8, 9]. Two-thirds of all CD patients will experience LOR to IFX or ADA [10]. The therapeutic options in cases of LOR to anti-TNF therapies are dose escalation (increase in dosage or in the frequency of treatment administration), switch to another anti-TNF treatment, addition of an immunosuppressant, or switch to another therapeutic class $[11,12]$.

Dose escalation of ADA is one of the most important options in refractory CD patients with LOR, and several studies have shown that it is an effective and well-tolerated therapeutic option in such cases [13-16]. ADA dose escalation resulted in a clinical response in about 60- 


\section{Case Reports in Gastroenterology}

Case Rep Gastroenterol 2019;13:37-49

DOI: $10.1159 / 000496453$

(c) 2019 The Author(s). Published by S. Karger AG, Basel www.karger.com/crg

Suzuki et al.: Adalimumab Dose-Escalation Therapy Is Effective in Refractory Crohn's Disease Patients with Loss of Response to Adalimumab, Especially in Cases without

Previous Infliximab Treatment

$80 \%$ of the CD cases $[13,17]$, but more than half of such CD patients will eventually experience LOR to ADA dose escalation [15]. However, there are few reports of ADA dose escalation in refractory CD patients with LOR to ADA, compared with those of IFX dose escalation in CD, especially in the East Asian area. In Japan, there is also little evidence regarding the effectiveness of ADA dose escalation in CD cases with LOR to ADA in the real world, since ADA dose escalation was finally approved in 2016 for use in CD. Recently, a multicenter study has demonstrated the efficacy and safety of escalation to ADA 80 mg every other week in Japanese patients with CD who lost response to maintenance ADA 40 mg every other week [18]. In refractory CD patients with LOR to ADA, it is very important to accumulate the evidence for ADA dose escalation in the real-world setting of anti-TNF treatment.

Therefore, in this study, the clinical response to ADA dose escalation of CD patients with LOR to ADA was evaluated retrospectively, using the CD activity index (CDAI) score, serum Creactive protein (CRP) levels, and endoscopic analyses in the real-world setting of anti-TNF treatment.

\section{Patients and Methods}

Between July 2016 and November 2017, active CD patients (CDAI $\geq 150$ or abnormal serum CRP elevation) with LOR to ADA were given subcutaneous ADA with dose escalation at Nagoya City University Hospital, Aichi Medical University Hospital, Kasugai Municipal Hospital, Nagoya City West Medical Center, Japanese Red Cross Nagoya Daini Hospital, and Gifu Prefectural Tajimi Hospital after the patients' informed consent was obtained. Before the start of ADA dose escalation, bacterial infectious enteritis was ruled out by stool cultures. Clostridium difficile infection was ruled out by $C$. difficile toxin testing and stool cultures. Cytomegalovirus infection was ruled out by pathological analysis of lesions $[3,19]$.

Intravenous IFX injections of $5 \mathrm{mg} / \mathrm{kg}$ were given as maintenance therapy every 8 weeks, in accordance with the Japanese protocol [20]. If the CD patients showed LOR to $5 \mathrm{mg} / \mathrm{kg}$ of IFX, the dose was escalated to $10 \mathrm{mg} / \mathrm{kg}$ [21]. In addition, regarding the CD cases with LOR to IFX, intravenous IFX injections of $5 \mathrm{mg} / \mathrm{kg}$ in weight that can be given at a minimum of every 4 weeks, the so-called period-shortening administration, was approved in Japan 2017. Subcutaneous doses of $40 \mathrm{mg}$ of ADA were given as maintenance therapy every other week, in accordance with the Japanese protocol [22]. If the CD patients showed LOR to $40 \mathrm{mg}$ of ADA, the $\mathrm{CD}$ patients received $80 \mathrm{mg}$ of ADA as dose escalation every other week, according to the Japanese protocol (Fig. 1).

LOR was defined as the conditions having 3 months or more followed by CDAI $\geq 150$ or abnormal serum CRP elevation without any infection.

\section{Symptoms and Laboratory Assessment}

Disease activity before and after subcutaneous ADA dose-escalation therapy was measured using the CDAI score $[3,4]$. Response was defined as a reduction of $\geq 70$ points $(70$-point response) or $\geq 100$ points (100-point response) from week 0 in the CDAI score, and remission was defined as a CDAI score $<150$ points $[3,4,23]$. The CDAI score was evaluated before this treatment, at weeks 12 and 52 after ADA dose escalation in CD patients with LOR to ADA. 
CRP was reported to correlate with disease activity [24]. Therefore, serum CRP levels (normal range $\leq 0.30 \mathrm{mg} / \mathrm{dL}$ ) were evaluated before this treatment and after 12 and 52 weeks of ADA dose escalation in CD patients with LOR to ADA.

\section{Endoscopic Assessment}

Colonoscopy or double balloon endoscopy was performed before and after ADA dose escalation in some CD patients with LOR to ADA. Endoscopic assessment of the lesions was performed according to the CDEIS: nonactivity, CDEIS $\leq 3$; mild active stage, $3 \leq$ CDEIS $<9$; moderate active stage, $9 \leq$ CDEIS $<12$; and severe active stage, CDEIS $\geq 12[3,25,26]$.

\section{Statistical Analyses}

The differences in CDAI scores and serum CRP levels between before this treatment and at 12 weeks or before this treatment and at 52 weeks after ADA dose escalation were assessed using the Wilcoxon signed-rank test in each group. $p$ values $<0.05$ were considered significant.

\section{Results}

\section{Patients' Characteristics}

A total of 203 CD patients received anti-TNF treatment (Fig. 1), with 78 receiving ADA and 125 patients receiving IFX as first-line anti-TNF treatment. No one received IFX injections of period-shortening administration in the present CD cases. Finally, 14 refractory CD patients with LOR to ADA received the ADA dose-escalation therapy. Of these 14 cases, 9 had ADA dose escalation after first-line ADA administration, 3 patients had ADA dose escalation after firstline IFX, second-line IFX dose escalation, and third-line ADA administration, and the remaining 2 cases had ADA dose escalation after first-line IFX and second-line ADA administration. A total of $12 \mathrm{CD}$ patients with ADA dose escalation were included in the final analysis, since 1 case transferred to a different hospital after 1 month of ADA dose escalation, and the remaining case had both $\mathrm{CDAI}<150$ and a normal serum CRP level when ADA dose escalation started.

The baseline characteristics of the 12 patients receiving subcutaneous ADA therapy are shown in Table 1. All patients received more than 3 months of ADA therapy. The male/female ratio was $7 / 5$, and the median ages at diagnosis and at start of therapy were 27.7 years (range 17-49) and 38.3 years (range 18-68), respectively. Median disease duration was 9.2 years (range 1-19). The 12 cases were divided into $2 \mathrm{~L} 1,1 \mathrm{~L} 2$, and $9 \mathrm{~L} 3$ types, according to the Montreal classification for CD. Six cases had perianal disease, and 4 cases had previous surgical resection. Regarding concomitant medication, 4 patients received prednisolone, 9 received 5aminosalicylates, 3 received immunosuppressants (azathioprine), 4 received granulocyte and monocyte adsorptive therapies, 7 received enteral nutrition, and none of them had received previous IFX or biologic drugs (Table 1). One patient had a peripheral nerve disorder after 4 months of ADA dose-escalation therapy that required termination of the therapy (Case 8, Table 2). Two cases had surgical resection within 1 year after ADA dose-escalation therapy, since the condition had worsened (Case 4 and Case 12, Table 2). 


\section{Case Reports in Gastroenterology}

Case Rep Gastroenterol 2019;13:37-49

DOI: $10.1159 / 000496453$

(c) 2019 The Author(s). Published by S. Karger AG, Basel www.karger.com/crg

Suzuki et al.: Adalimumab Dose-Escalation Therapy Is Effective in Refractory Crohn's Disease Patients with Loss of Response to Adalimumab, Especially in Cases without

Previous Infliximab Treatment

\section{CDAI Scores and CRP Levels at 12 Weeks}

The mean CDAI score decreased from $194 \pm 27$ (average \pm SE) at the start of subcutaneous ADA dose-escalation therapy to $143 \pm 16$ at week 12 in the 12 CD patients with LOR to ADA, but the difference was not significant ( $1>0.05$; Table 2). Four (33\%) and $4(33 \%)$ CD cases achieved 70-point and 100-point responses, respectively, at week 12 after ADA dose-escalation therapy started. Eight (67\%) patients showed clinical remission at week 12 after ADA dose-escalation therapy started.

In CD patients without previous IFX treatment, the mean CDAI score was significantly decreased from $226 \pm 34$ (average \pm SE) at the start of subcutaneous ADA dose-escalation therapy to $144 \pm 21$ at week 12 in the 8 CD patients with LOR to ADA ( $p=0.043$; Table 2). Four $(50 \%)$ and $4(50 \%)$ CD cases achieved 70-point and 100-point responses, respectively, at week 12 after ADA therapy dose escalation started. Five (63\%) patients showed clinical remission at week 12 after ADA dose-escalation therapy started.

In the CD patients with previous IFX exposure, the mean CDAI scores before and at week 12 of ADA dose escalation were $132 \pm 19$ and $140 \pm 23$, respectively, in the 4 CD patients with LOR to ADA ( $p>0.05$; Table 2). Two (50\%) patients showed clinical remission at week 12 after ADA dose-escalation therapy started in the group with previous IFX exposure.

The mean CRP (normal range $\leq 0.30 \mathrm{mg} / \mathrm{dL}$ ) decreased significantly from $1.62 \pm 0.67$ $\mathrm{mg} / \mathrm{dL}$ (average $\pm \mathrm{SE}$ ) at the start of subcutaneous ADA dose-escalation therapy to $0.76 \pm 0.30$ $\mathrm{mg} / \mathrm{dL}$ at week 12 in the $12 \mathrm{CD}$ patients with LOR to ADA ( $p=0.011$, Table 2$)$. In the CD patients without previous IFX treatment, the mean CRP decreased significantly from $1.23 \pm 0.79$ $\mathrm{mg} / \mathrm{dL}$ at the start of subcutaneous ADA dose-escalation therapy to $0.51 \pm 0.31 \mathrm{mg} / \mathrm{dL}$ at week 12 in the $8 \mathrm{CD}$ patients LOR to ADA ( $p=0.036$, Table 2$)$. In the CD patients with previous IFX exposure, the mean CRP decreased from $2.39 \pm 1.29 \mathrm{mg} / \mathrm{dL}$ at the start of subcutaneous ADA dose-escalation therapy to $1.26 \pm 0.65 \mathrm{mg} / \mathrm{dL}$ at week 12 in the $4 \mathrm{CD}$ patients LOR to ADA, but there was no significant difference $(p>0.05$, Table 2$)$.

\section{CDAI Scores and CRP Levels at 52 Weeks}

Among the $12 \mathrm{CD}$ patients with ADA dose escalation, CDAI scores and CRP levels were evaluated at week 52 in 9 cases (Table 2). The mean CDAI score decreased from $190 \pm 34$ (average \pm SE) at the start of subcutaneous ADA dose-escalation therapy to $140 \pm 24$ at week 52 in the 9 CD patients with LOR to ADA, but the difference was not significant ( $p>0.05$; Table $2)$. Three (33\%) and $2(22 \%)$ CD cases achieved 70-point and 100-point responses, respectively, at week 52 after ADA dose-escalation therapy started. Six (67\%) patients showed clinical remission at week 52 after ADA dose-escalation therapy started.

In CD patients without previous IFX treatment, the mean CDAI score was significantly decreased from $224 \pm 45$ (average \pm SE) at the start of subcutaneous ADA dose-escalation therapy to $126 \pm 21$ at week 52 in the 6 CD patients with LOR to ADA ( $p=0.028$; Table 2$)$. Three (50\%) and 2 (33\%) CD cases achieved 70-point and 100-point responses, respectively, at week 52 after ADA therapy dose escalation started. Four (67\%) patients showed clinical remission at week 52 after ADA dose-escalation therapy started.

In the CD patients with previous IFX exposure, the mean CDAI scores before and at week 52 of ADA dose escalation were $122 \pm 23$ and $167 \pm 65$, respectively, in the 3 CD patients with LOR to ADA ( $p>0.05$; Table 2). Two (67\%) patients showed clinical remission at week 52 after ADA dose-escalation therapy started in the group with previous IFX exposure. 


\section{Case Reports in Gastroenterology}

Case Rep Gastroenterol 2019;13:37-49

DOI: $10.1159 / 000496453$

(c) 2019 The Author(s). Published by S. Karger AG, Base www.karger.com/crg

Suzuki et al.: Adalimumab Dose-Escalation Therapy Is Effective in Refractory Crohn's Disease Patients with Loss of Response to Adalimumab, Especially in Cases without

Previous Infliximab Treatment

The mean CRP (normal range $\leq 0.30 \mathrm{mg} / \mathrm{dL}$ ) decreased significantly from $1.28 \pm 0.70$ $\mathrm{mg} / \mathrm{dL}$ (average $\pm \mathrm{SE}$ ) at the start of subcutaneous ADA dose-escalation therapy to $0.32 \pm 0.11$ $\mathrm{mg} / \mathrm{dL}$ at week 52 in the $9 \mathrm{CD}$ patients with LOR to ADA ( $p=0.029$, Table 2$)$. In the CD patients without previous IFX treatment, the mean CRP decreased significantly from $1.35 \pm 1.07 \mathrm{mg} / \mathrm{dL}$ at the start of subcutaneous ADA dose-escalation therapy to $0.14 \pm 0.06 \mathrm{mg} / \mathrm{dL}$ at week $52 \mathrm{in}$ the 6 CD patients LOR to ADA ( $p=0.028$, Table 2 ). In the CD patients with previous IFX exposure, the mean CRP decreased from $1.13 \pm 0.45 \mathrm{mg} / \mathrm{dL}$ at the start of subcutaneous ADA doseescalation therapy to $0.68 \pm 0.14 \mathrm{mg} / \mathrm{dL}$ at week 52 in the $3 \mathrm{CD}$ patients LOR to ADA, but there was no significant difference ( $p>0.05$, Table 2$)$.

\section{CDEIS}

Among the 12 CD patients with ADA dose escalation, 3 cases (Case 2, Case 5, and Case 9, Table 2) could be evaluated endoscopically before and after the ADA dose escalation. In Case 2 , inflammatory lesions (CDEIS $=9$ ) were detected before ADA dose escalation, and endoscopic mucosal healing was observed after the therapy. In Case 5 , inflammatory lesions (CDEIS = 11) were detected before ADA dose escalation, and mucosal healing was observed endoscopically after the therapy (Fig. 2). In Case 9, inflammatory lesions (CDEIS $=11$ ) were detected before ADA dose escalation, but the lesions were not improved by the therapy, which was switched to another therapeutic class (ustekinumab, anti-interleukin-12/23 p40 monoclonal antibody).

\section{Discussion}

The results of the present study show that serum CRP levels were significantly reduced from the start to week 12 and week 52 of ADA dose-escalation therapy in all CD cases with LOR to ADA (Table 2). Sixty seven percent of the patients showed clinical remission at week 12 after ADA dose-escalation therapy started, suggesting the excellent effectiveness of induction in all CD patients with LOR to ADA, although there were no significant reductions of CDAI scores at week 12 and week 52 compared with those before ADA dose-escalation therapy. A clinical response was observed in 99/124 (79\%) CD patients at 3 months and in 62/107 (61\%) CD patients at 12 months [13] and another Japanese paper shows that a clinical response was observed in 25/28 (89\%) CD patients at 8 weeks and in 18/28 (64\%) CD patients at 12 months [18]. In the ADA dose-escalation sub-cohort (ADA 80 mg every other week), the clinical remission rate was 75\% (6/8) 48 weeks after ADA dose escalation in Japanese CD patients [16]. ADA dose escalation is one of the most important therapeutic options in CD patients with LOR to ADA. On multivariate analysis, $40 \mathrm{mg}$ every week rather than $80 \mathrm{mg}$ every other week was significantly associated with a clinical response to ADA dose escalation at 12 months [13]. ADA dose escalation (40 mg weekly) was clinically beneficial for children with CD who experienced nonresponse or flare on every other week dosing [14]. Adjustment to weekly ADA dosing has been shown to be a benefit for adults with $\mathrm{CD}$ and ulcerative colitis who have lost response or who had an inadequate response to therapy [14, 17, 27]. In Japan, ADA dose escalation with $80 \mathrm{mg}$ every other week is approved, but that of $40 \mathrm{mg}$ every week is unfortunately not approved. In many Western and Asian countries, ADA dose escalation of 


\section{Case Reports in Gastroenterology}

Case Rep Gastroenterol 2019;13:37-49

DOI: $10.1159 / 000496453$

(c) 2019 The Author(s). Published by S. Karger AG, Basel www.karger.com/crg

Suzuki et al.: Adalimumab Dose-Escalation Therapy Is Effective in Refractory Crohn's Disease Patients with Loss of Response to Adalimumab, Especially in Cases without

Previous Infliximab Treatment

$40 \mathrm{mg}$ every week can be used in CD patients with LOR to ADA, and we are hoping for the approval of this ADA dose-escalation regimen in Japan.

In our present study, ADA dose escalation was more effective for CD patients without previous IFX treatment than for those with previous IFX exposure. The serum CRP levels were significantly reduced from the start to week 12 and week 52 of ADA dose-escalation therapy in the CD cases without previous IFX treatment, although the serum CRP levels have been positive before, at week 12 and at week 52 after ADA dose escalation in all cases with previous IFX exposure (Table 2). A significantly higher rate of clinical remission was achieved with ADA dose escalation (40 mg weekly) in IFX-naïve CD patients with LOR to ADA high-dose administration (20-40 mg every other week) than in those with LOR to ADA low-dose administration (10-20 mg every other week), while there were no significant differences between the high and low-dose groups in the IFX-experienced CD patients, suggesting that ADA dose escalation is more effective for IFX-naïve CD patients than for IFX-experienced ones [14]. However, previous anti-TNF exposure (IFX or certolizumab use) was not associated with the risk factors predicting response to ADA dose escalation or tertiary LOR after ADA dose escalation, although previous anti-TNF exposure and elevated CRP predicted earlier time to tertiary LOR to ADA dose escalation [15]. Regarding the predictive factors of response of ADA dose escalation, LOR that developed after $\geq 10$ months and disease with strictures were significantly associated with a clinical response to ADA dose escalation at 3 months, suggesting that previous anti-TNF treatment (IFX or certolizumab use) was not associated with the clinical response to ADA dose escalation at 3 months on multivariate analysis [13]. On multivariate analysis, $40 \mathrm{mg}$ every week rather than $80 \mathrm{mg}$ every other week and a CRP level $\leq 5 \mathrm{mg} / \mathrm{L}$ at ADA dose escalation were significantly associated with clinical response to ADA dose escalation at 12 months, suggesting that previous anti-TNF treatment (IFX or certolizumab use) was not associated with the clinical response to ADA dose escalation at 12 months [13]. In Japan regarding the predictive factors, the rates of clinical remission in IFX-naïve patients were numerically higher compared to IFX-experienced patients, although prior use of IFX was not significant in the logistic regression analysis of clinical remission [18]. Further large-scale studies may be needed to clarify the comparison between CD patients with and without previous IFX exposure among CD patients with LOR to ADA from the perspective of the effectiveness of ADA dose escalation, since our study was small-scale one. In addition, further large-scale studies may be also needed to evaluate the clinical factors related to response of ADA dose escalation.

In the present study, endoscopic mucosal healing was seen after ADA dose escalation in CD patients with LOR to ADA. In 2 cases without previous IFX treatment, inflammatory lesions were seen before the ADA dose escalation, and endoscopic mucosal healing was observed after the therapy. However, lesions were not improved by the ADA dose escalation in one case with previous IFX treatment. To the best of our knowledge, there have been no reports of the evaluation of the endoscopic findings in ADA dose escalation of CD patients with LOR to ADA. Regarding normal ADA administration, mucosal healing is an increasingly important therapeutic goal in the treatment of patients with $\operatorname{CD}[26,28,29]$. However, it is difficult to achieve endoscopic mucosal healing, as compared to clinical remission. Following induction therapy with ADA, CD patients who continue to receive ADA are more likely to achieve mucosal healing than those given placebo [26]. In the EXTEND Trial, 27 and 24\% of the CD patients receiving ADA had mucosal healing at 12 and 52 weeks, respectively [26]. We consider that it is 
important to evaluate whether endoscopic mucosal healing is achieved from the perspective of deep remission in CD cases with ADA dose escalation.

Regarding to biologics switching of anti-TNF treatment, it is well-known that the serum trough level of IFX and ADA predicts clinical outcome, and that LOR is related to a decrease in serum trough concentration $[20,30]$. We have also shown the importance of analysis of IFX trough level in the CD patients with the switch from ADA to IFX [22], although the trough concentration of ADA could not be evaluated in the present study from the viewpoint of the ADA dose escalation.

In conclusion, ADA dose-escalation therapy was effective in refractory $\mathrm{CD}$ patients with LOR to ADA, especially in cases without previous IFX treatment.

\section{Acknowledgements}

This study was supported by a Grant-in-Aid (Kiban C, 17K09355) from the Ministry of Education, Culture, Sports, Science, and Technology of Japan.

\section{Statement of Ethics}

This study was approved by the Institutional Review Board at each participating hospital and was in accordance with the guidelines of the International Conference on Harmonization and ethical principles originating in the Declaration of Helsinki. Informed consent was obtained from the patients..

\section{Disclosure Statement}

The authors have no conflicts of interest to declare.

\section{References}

1 Pariente B, Mary JY, Danese S, Chowers Y, De Cruz P, D'Haens G, et al. Development of the Lémann index to assess digestive tract damage in patients with Crohn's disease. Gastroenterology. 2015 Jan;148(1):52-63.e3.

2 Peyrin-Biroulet L, Cieza A, Sandborn WJ, Kostanjsek N, Kamm MA, Hibi T, et al. Disability in inflammatory bowel diseases: developing ICF Core Sets for patients with inflammatory bowel diseases based on the International Classification of Functioning, Disability, and Health. Inflamm Bowel Dis. 2010 Jan;16(1):15-22.

3 Mizoshita T, Tanida S, Tsukamoto H, Ozeki K, Katano T, Nishiwaki H, et al. Adalimumab Treatment in Biologically Naïve Crohn's Disease: Relationship with Ectopic MUC5AC Expression and Endoscopic Improvement. Gastroenterol Res Pract. 2014;2014:687257.

4 Hanauer SB, Sandborn WJ, Rutgeerts P, Fedorak RN, Lukas M, MacIntosh D, et al. Human anti-tumor necrosis factor monoclonal antibody (adalimumab) in Crohn's disease: the CLASSIC-I trial. Gastroenterology. 2006 Feb;130(2):323-33; quiz 591.

5 Sandborn WJ, Hanauer SB, Rutgeerts P, Fedorak RN, Lukas M, MacIntosh DG, et al. Adalimumab for maintenance treatment of Crohn's disease: results of the CLASSIC II trial. Gut. 2007 Sep;56(9):1232-9. 
Suzuki et al.: Adalimumab Dose-Escalation Therapy Is Effective in Refractory Crohn's Disease Patients with Loss of Response to Adalimumab, Especially in Cases without

Previous Infliximab Treatment

6 Watanabe M, Hibi T, Lomax KG, Paulson SK, Chao J, Alam MS, et al.; Study Investigators. Adalimumab for the induction and maintenance of clinical remission in Japanese patients with Crohn's disease. J Crohn's Colitis. 2012 Mar;6(2):160-73.

7 Gisbert JP, Panés J. Loss of response and requirement of infliximab dose intensification in Crohn's disease: a review. Am J Gastroenterol. 2009 Mar;104(3):760-7.

8 Ben-Horin S, Chowers Y. Review article: loss of response to anti-TNF treatments in Crohn's disease. Aliment Pharmacol Ther. 2011 May;33(9):987-95.

9 Billioud V, Sandborn WJ, Peyrin-Biroulet L. Loss of response and need for adalimumab dose intensification in Crohn's disease: a systematic review. Am J Gastroenterol. 2011 Apr;106(4):674-84.

10 Gisbert JP, Marín AC, McNicholl AG, Chaparro M. Systematic review with meta-analysis: the efficacy of a second anti-TNF in patients with inflammatory bowel disease whose previous anti-TNF treatment has failed. Aliment Pharmacol Ther. 2015 Apr;41(7):613-23.

11 Ben-Horin S, Waterman M, Kopylov U, Yavzori M, Picard O, Fudim E, et al. Addition of an immunomodulator to infliximab therapy eliminates antidrug antibodies in serum and restores clinical response of patients with inflammatory bowel disease. Clin Gastroenterol Hepatol. 2013 Apr;11(4):444-7.

12 Chowers Y, Sturm A, Sans M, Papadakis K, Gazouli M, Harbord M, et al. Report of the ECCO workshop on antiTNF therapy failures in inflammatory bowel diseases: biological roles and effects of TNF and TNF antagonists. J Crohn's Colitis. 2010 Oct;4(4):367-76.

13 Duveau N, Nachury M, Gerard R, Branche J, Maunoury V, Boualit M, et al. Adalimumab dose escalation is effective and well tolerated in Crohn's disease patients with secondary loss of response to adalimumab. Dig Liver Dis. 2017 Feb;49(2):163-169.

14 Dubinsky MC, Rosh J, Faubion WA Jr, Kierkus J, Ruemmele F, Hyams JS, et al. Efficacy and Safety of Escalation of Adalimumab Therapy to Weekly Dosing in Pediatric Patients with Crohn's Disease. Inflamm Bowel Dis. 2016 Apr;22(4):886-93.

15 Ma C, Huang V, Fedorak DK, Kroeker KI, Dieleman LA, Halloran BP, et al. Adalimumab dose escalation is effective for managing secondary loss of response in Crohn's disease. Aliment Pharmacol Ther. 2014 Nov;40(9):1044-55.

16 Watanabe M, Hibi T, Mostafa NM, Chao J, Arora V, Camez A, et al. Long-term safety and efficacy of adalimumab in Japanese patients with moderate to severe Crohn's disease. J Crohn's Colitis. 2014 Nov;8(11):1407-16.

17 Sandborn WJ, Colombel JF, Schreiber S, Plevy SE, Pollack PF, Robinson AM, et al. Dosage adjustment during long-term adalimumab treatment for Crohn's disease: clinical efficacy and pharmacoeconomics. Inflamm Bowel Dis. 2011 Jan;17(1):141-51.

18 Motoya S, Watanabe M, Wallace K, Lazar A, Nishimura Y, Ozawa M, et al. Efficacy and Safety of Dose Escalation to Adalimumab $80 \mathrm{mg}$ Every Other Week in Japanese Patients with Crohn's Disease Who Lost Response to Maintenance Therapy. Inflamm Intest Dis. 2018 Jul;2(4):228-35.

19 Mizoshita T, Tanida S, Tsukamoto H, Ozeki K, Katano T, Ebi M, et al. Colon Mucosa Exhibits Loss of Ectopic MUC5AC Expression in Patients with Ulcerative Colitis Treated with Oral Tacrolimus. ISRN Gastroenterol. 2013 Apr;2013:304894.

20 Hibi T, Sakuraba A, Watanabe M, Motoya S, Ito H, Motegi K, et al. Retrieval of serum infliximab level by shortening the maintenance infusion interval is correlated with clinical efficacy in Crohn's disease. Inflamm Bowel Dis. 2012 Aug;18(8):1480-7.

21 Suzuki Y, Matsui T, Ito H, Ashida T, Nakamura S, Motoya S, et al. Circulating Interleukin 6 and Albumin, and Infliximab Levels Are Good Predictors of Recovering Efficacy After Dose Escalation Infliximab Therapy in Patients with Loss of Response to Treatment for Crohn's Disease: A Prospective Clinical Trial. Inflamm Bowel Dis. 2015 Sep;21(9):2114-22.

22 Mizoshita T, Tanida S, Ozeki K, Katano T, Shimura T, Mori Y, et al. Long-Term Clinical Remission in Biologically Naïve Crohn's Disease Patients with Adalimumab Therapy, Including Analyses of Switch from Adalimumab to Infliximab. Case Rep Gastroenterol. 2016 Jun;10(2):283-91.

23 Best WR, Becktel JM, Singleton JW, Kern F Jr. Development of a Crohn's disease activity index. National Cooperative Crohn's Disease Study. Gastroenterology. 1976 Mar;70(3):439-44.

24 Ueno F, Matsui T, Matsumoto T, Matsuoka K, Watanabe M, Hibi T; Guidelines Project Group of the Research Group of Intractable Inflammatory Bowel Disease subsidized by the Ministry of Health, Labour and Welfare of Japan and the Guidelines Committee of the Japanese Society of Gastroenterology. Evidence-based clinical practice guidelines for Crohn's disease, integrated with formal consensus of experts in Japan. J Gastroenterol. 2013 Jan;48(1):31-72. 


\section{Case Reports in Gastroenterology}

\begin{tabular}{l|l}
\hline Case Rep Gastroenterol 2019;13:37-49 \\
\hline DOI: 10.1159/000496453 & $\begin{array}{l}\text { @ 2019 The Author(s). Published by S. Karger AG, Basel } \\
\text { www.karger.com/crg }\end{array}$
\end{tabular}

Suzuki et al.: Adalimumab Dose-Escalation Therapy Is Effective in Refractory Crohn's Disease Patients with Loss of Response to Adalimumab, Especially in Cases without Previous Infliximab Treatment

25 Mary JY, Modigliani R. Development and validation of an endoscopic index of the severity for Crohn's disease: a prospective multicentre study. Groupe d'Etudes Thérapeutiques des Affections Inflammatoires du Tube Digestif (GETAID). Gut. 1989 Jul;30(7):983-9.

26 Rutgeerts P, Van Assche G, Sandborn WJ, Wolf DC, Geboes K, Colombel JF, et al. Adalimumab induces and maintains mucosal healing in patients with Crohn's disease: data from the EXTEND trial. Gastroenterology. 2012 May;142(5):1102-1111 e2.

27 Wolf D, D'Haens G, Sandborn WJ, Colombel JF, Van Assche G, Robinson AM, et al. Escalation to weekly dosing recaptures response in adalimumab-treated patients with moderately to severely active ulcerative colitis. Aliment Pharmacol Ther. 2014 Sep;40(5):486-97.

28 Rutgeerts P, Vermeire S, Van Assche G. Mucosal healing in inflammatory bowel disease: impossible ideal or therapeutic target? Gut. 2007 Apr;56(4):453-5.

29 D'Haens GR, Fedorak R, Lémann M, Feagan BG, Kamm MA, Cosnes J, et al.; IOIBD Membership. Endpoints for clinical trials evaluating disease modification and structural damage in adults with Crohn's disease. Inflamm Bowel Dis. 2009 Oct;15(10):1599-604.

30 Roblin X, Rinaudo M, Del Tedesco E, Phelip JM, Genin C, Peyrin-Biroulet L, et al. Development of an algorithm incorporating pharmacokinetics of adalimumab in inflammatory bowel diseases. Am J Gastroenterol. 2014 Aug;109(8):1250-6.

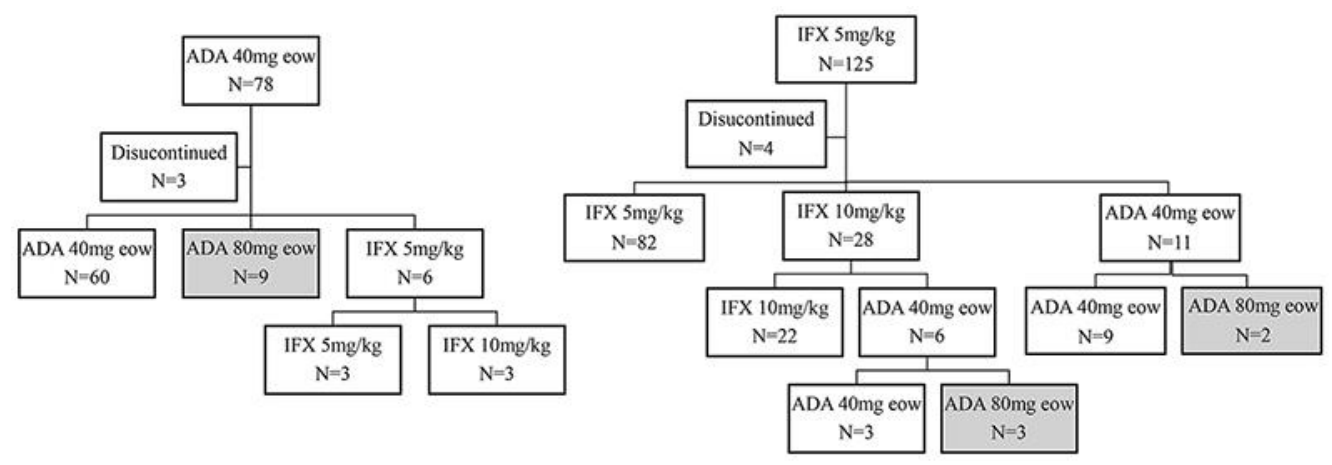

Fig. 1. Disposition and flow of patients. ADA, adalimumab; IFX, infliximab; eow, every other week. 


\section{Case Reports in Gastroenterology}

Case Rep Gastroenterol 2019;13:37-49

(C) 2019 The Author(s). Published by S. Karger AG, Basel www.karger.com/crg

Suzuki et al.: Adalimumab Dose-Escalation Therapy Is Effective in Refractory Crohn's Disease Patients with Loss of Response to Adalimumab, Especially in Cases without Previous Infliximab Treatment
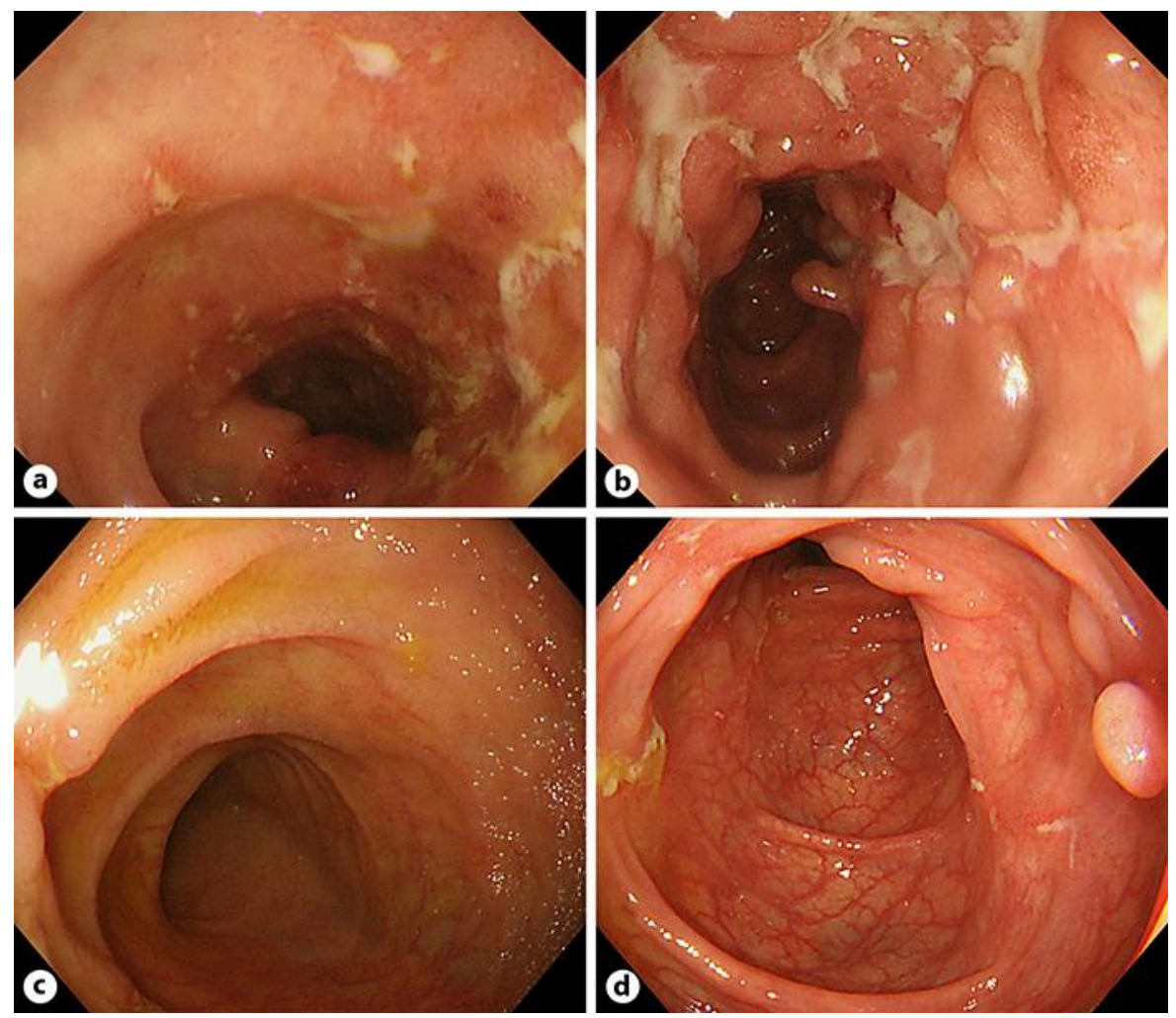

Fig. 2. Longitudinal and serpiginous (snake-like) ulcers are seen endoscopically in the terminal ileum (a) and transverse colon (b) before ADA dose-escalation therapy, and the lesions show mucosal healing in the terminal ileum (c) and transverse colon (d) after ADA dose-escalation therapy. 


\begin{tabular}{l|l}
\hline Case Rep Gastroenterol 2019;13:37-49 \\
\hline DOI: 10.1159/000496453 & $\begin{array}{l}\text { @ 2019 The Author(s). Published by S. Karger AG, Basel } \\
\text { www.karger.com/crg }\end{array}$ \\
\hline
\end{tabular}

Suzuki et al.: Adalimumab Dose-Escalation Therapy Is Effective in Refractory Crohn's Disease Patients with Loss of Response to Adalimumab, Especially in Cases without Previous Infliximab Treatment

Table 1. Patients' baseline characteristics $(N=12)$

\section{Sex, male/female}

Median age at diagnosis (range), years

Median age at start of the therapy (range), years

Median disease duration (range), years

Extent of disease

L1

L2

L3

Perianal disease

Previous surgical resection

Concomitant medication

Prednisolone

5-aminosalicylates

Immunosuppressants (AZA)

GMA

Enteral nutrition
$7 / 5$

27.7 (17-49)

$38.3(18-68)$

$9.2(1-19)$

2 (17)

1 (8)

$9(75)$

$6(50)$

4 (33)

4
9
3
4
7

Values are presented as $n(\%)$ or $n$; unless otherwise stated. AZA, azathioprine; GMA, absorptive granulocyte and monocyte apheresis; L1, ileum; L2, colon; L3, ileocolon. 


\section{Case Reports in Gastroenterology}

\begin{tabular}{l|l} 
DOI: $10.1159 / 000496453$ & (c 2019 The Author(s). Published by S. Karger AG, Basel
\end{tabular} www.karger.com/crg

Suzuki et al.: Adalimumab Dose-Escalation Therapy Is Effective in Refractory Crohn's Disease Patients with Loss of Response to Adalimumab, Especially in Cases without Previous Infliximab Treatment

Table 2. Relationship between CDAI and CRP before and at week 12 after ADA dose escalation in CD patients with LOR to ADA

\begin{tabular}{|c|c|c|c|c|c|c|c|c|c|c|c|}
\hline \multirow[t]{2}{*}{ Case } & \multirow{2}{*}{$\begin{array}{l}\text { Age, } \\
\text { years }\end{array}$} & \multirow[t]{2}{*}{ Sex } & \multirow{2}{*}{$\begin{array}{l}\text { Anti-TNF } \\
\text { treatments } \\
\text { before ADA } \\
\text { dose escalation }\end{array}$} & \multirow{2}{*}{$\begin{array}{l}\text { Duration of } \\
\text { anti-TNF } \\
\text { treatments } \\
\text { before ADA } \\
\text { dose escala- } \\
\text { tion, months }\end{array}$} & \multirow{2}{*}{$\begin{array}{l}\text { Stric- } \\
\text { tures }\end{array}$} & \multicolumn{3}{|l|}{ CDAIa , b } & \multicolumn{3}{|c|}{ CRPc, d, e, f } \\
\hline & & & & & & $\begin{array}{l}0 \\
\text { weeks }\end{array}$ & $\begin{array}{l}12 \\
\text { weeks }\end{array}$ & $\begin{array}{l}52 \\
\text { weeks }\end{array}$ & $\begin{array}{l}0 \\
\text { weeks }\end{array}$ & $\begin{array}{l}12 \\
\text { weeks }\end{array}$ & $\begin{array}{l}52 \\
\text { weeks }\end{array}$ \\
\hline Case 1 & 32 & M & ADA & 7 & - & mild & remission & remission & - & - & - \\
\hline Case 2 & 18 & $\mathrm{~F}$ & $\mathrm{ADA}$ & 4 & - & mild & remission & remission & - & - & - \\
\hline Case 3 & 27 & M & $\mathrm{ADA}$ & 16 & - & remission & remission & remission & + & - & - \\
\hline Case 4 & 20 & M & $\mathrm{ADA}$ & 3 & - & mild & mild & & + & + & \\
\hline Case 5 & 25 & M & $\mathrm{ADA}$ & 11 & - & moderate & remission & remission & + & - & - \\
\hline Case 6 & 41 & M & $\mathrm{ADA}$ & 33 & - & moderate & moderate & mild & + & + & - \\
\hline Case 7 & 52 & $\mathrm{~F}$ & $\mathrm{ADA}$ & 3 & + & mild & mild & mild & + & + & + \\
\hline Case 8 & 32 & M & $\mathrm{ADA}$ & 22 & + & moderate & remission & & + & - & \\
\hline Case 9 & 69 & $\mathrm{~F}$ & $\mathrm{IFX} \rightarrow \mathrm{ADA}$ & 53 & - & mild & mild & moderate & + & + & + \\
\hline Case 10 & 37 & M & $\begin{array}{l}\text { IFX } \rightarrow \text { IFX dose } \\
\text { escalation } \rightarrow \text { ADA }\end{array}$ & 149 & - & remission & remission & remission & + & + & + \\
\hline Case 11 & 47 & $\mathrm{~F}$ & $\begin{array}{l}\mathrm{IFX} \rightarrow \mathrm{IFX} \text { dose } \\
\text { escalation } \rightarrow \text { ADA }\end{array}$ & 122 & + & remission & remission & remission & + & + & + \\
\hline Case 12 & 32 & $\mathrm{~F}$ & $\begin{array}{l}\text { IFX } \rightarrow \text { IFX dose } \\
\text { escalation } \rightarrow \text { ADA }\end{array}$ & 56 & + & mild & remission & & + & + & \\
\hline
\end{tabular}

CDAI: remission: score <150; mild: $150 \leq$ score <220; moderate: $220 \leq$ score <450; severe: score $\geq 450$. CRP: $-: \leq 0.30 \mathrm{mg} / \mathrm{dL}$; : $>0.30$ $\mathrm{mg} / \mathrm{dL}$. ${ }^{\mathrm{C}} \mathrm{CDAI}$ before and at week 12 after ADA dose escalation, $p<0.05$ in the group without previous IFX treatment. $\mathrm{b}$ CDAI before and at week 52 after ADA dose escalation, $p<0.05$ in the group without previous IFX treatment. c CRP level before and at week 12 after ADA dose escalation, $p<0.05$ in the whole group. $\mathrm{d}$ CRP level before and at week 52 after ADA dose escalation, $p<0.05$ in the whole group. $\mathrm{e}$ CRP level before and at week 12 after ADA dose escalation, $p<0.05$ in the group without previous IFX treatment. ${ }^{\mathrm{f}} \mathrm{CRP}$ level before and at week 52 after ADA dose escalation, $p<0.05$ in the group without previous IFX treatment. 